\title{
Egg-shell Treated Oil Palm Fronds (EG-OPF) as Low-Cost Adsorbent for Methylene Blue Removal
}

\author{
Rosalyza Hasan ${ }^{1}$, Nur Aida Farihin Ahliyasah ${ }^{1}$, Chi Cheng Chong1, Rohayu Jusoh¹, \\ Herma Dina Setiabudi ${ }^{1,2, *}$ \\ ${ }^{1}$ Faculty of Chemical and Natural Resources Engineering, Universiti Malaysia Pahang, 26300 \\ Gambang, Kuantan, Pahang, Malaysia \\ ${ }^{2}$ Centre of Excellence for Advanced Research in Fluid Flow, Universiti Malaysia Pahang, 26300 \\ Gambang, Kuantan, Pahang, Malaysia
}

Received: 1st October 2018; Revised: 28th October 2018; Accepted: 14th November 2018; Available online: 25th January 2019; Published regularly: April 2019

\begin{abstract}
A new adsorbent (egg-shell treated oil palm fronds (EG-OPF)) prepared from wastes was evaluated for methylene blue (MB) removal. Optimization among three significant variables (initial concentration $\left(X_{1}\right)$, initial $\mathrm{pH}\left(X_{2}\right)$, and adsorbent dosage $\left(X_{3}\right)$ ) were executed using response surface methodology (RSM). The most excellent performance was marked at $X_{1}=291.7 \mathrm{mg} / \mathrm{L}, X_{2}=\mathrm{pH} 5$, and $X_{3}=1.82 \mathrm{~g} / \mathrm{L}$, with MB removal of $80.26 \%$. The kinetic study was fitted perfectly with the pseudo-second-order model $\left(R^{2}>0.990\right)$, indicating the chemisorption process. The isotherm study was found to follow the Langmuir isotherm model $\left(R^{2}=0.999\right)$, with maximal adsorption magnitude of $714.3 \mathrm{mg} / \mathrm{g}$, implying the monolayer adsorption on a homogenous adsorbent surface. The reusability study affirmed the feasibility of EG-OPF in MB removal, credited to its excellent performance during reusability studies. The present study successfully discovered a new low-cost adsorbent (EG-OPF) for MB removal. Copyright $\mathbb{C}$ 2019 BCREC Group. All rights reserved
\end{abstract}

Keywords: Adsorption; Low-Cost Adsorbent; Optimization; Methylene Blue

How to Cite: Hasan, R., Ahliyasah, N.A.F., Chong, C.C., Jusoh, R., Setiabudi, H.D. (2019). Egg-shell Treated Oil Palm Fronds (EG-OPF) as Low-Cost Adsorbent for Methylene Blue Removal. Bulletin of Chemical Reaction Engineering \& Catalysis, 14 (1): 158-164 (doi:10.9767/bcrec.14.1.3322.158-164)

Permalink/DOI: https://doi.org/10.9767/bcrec.14.1.3322.158-164

\section{Introduction}

Dyes are one of the most important materials in textile, printing, food, rubber, and paper industries to increase the attractiveness of a product. After Perkin discovered the first synthetic dye in 1856, a vast variety of synthetic dyes were developed to meet the high demand in industries [1,2] and there are around 10,000

\footnotetext{
* Corresponding Author.

E-mail: herma@ump.edu.my (H.D. Setiabudi)

Telp: +60-9-5492836, Fax: +60-9-5492889
}

different commercial dyes existing worldwide. Methylene blue (MB) is a basic dye that broadly adopted in the dying process. During the dyeing processes, around $10-15 \%$ of the MB was discharged [3] and appeared as a problematic concern owing to its toxicity [4]. Thus, it is utmost important to eliminate the MB before being discarded to receiving water.

There are various treatment processes to remove MB including membrane filtration [5], electrochemical treatment [6], and adsorption [7]. Among the above mentioned processes, adsorption has attracted considerable attention 
owing to its simplicity and worth for its economic value [8]. The adsorption processes usually involved the use of activated carbon as an adsorbent, however, there are some drawbacks to this material which involved high manufacturing and regeneration cost [9]. For that reason, researchers tended to replace the existing activated carbon by producing effective adsorbent from either agricultural or industrial solid wastes.

As the major industry in Malaysia, palm oil industry generated approximately 30 million tons of fronds, trunks, empty fruit bunches and leaves per year [10]. The abundance of these wastes generated serious environmental pollution due to improper waste management [11]. Thus, it is advantageous to utilize oil palm frond (OPF) as a new adsorbent for MB removal. It has been reported that the efficiency of the low-cost adsorbent can be improved by alkaline treatment due to the improvement in polarity of the surface and the sorption sites' density [12]. However, alkaline treatment is considered to be costly owing to the high price of the chemical. Thus, the utilization of eggshell (EG) waste which consists of a high composition of $\mathrm{CaCO}_{3}$ could consider as an alternative material for alkaline treatment owing to its low cost and availability. Moreover, as far as we are concerned, there is no study has been done on OPF treated by EG to perform an economical and practical approach for MB removal. Thus, in this study, egg-shell treated oil palm fronds (EG-OPF) was evaluated for the MB removal and its performance was optimized using response surface methodology (RSM).

\section{Materials and Method}

2.1 Preparation and Characterization of Adsorbent

Oil palm frond (OPF) and eggshells (EG) were collected in Pahang, Malaysia. The OPF was cut into small pieces $(10-20 \mathrm{~mm})$, soaked in distilled water $(12 \mathrm{~h})$, oven-dried $\left(80^{\circ} \mathrm{C}, 24 \mathrm{~h}\right)$, followed by crushed and sieved (355-500 $\mathrm{\mu m}$ ). Subsequently, the EG were washed with distilled water, oven-dried $\left(80^{\circ} \mathrm{C}, 24 \mathrm{~h}\right)$ and calcined $\left(950{ }^{\circ} \mathrm{C}, 3 \mathrm{~h}\right)$. The dried eggshells were grounded and sieved into powder with particles size $355-500 \mu \mathrm{m}$. XRF analysis confirmed that calcined EG mainly consists of $\mathrm{CaO}(97.44 \%)$ as shown in Table 1, which decomposed from $\mathrm{CaCO}_{3}$ via calcination.

For the pre-treatment of OPF with EG, $8.6 \mathrm{~g}$ of calcined EG powder was added to $1 \mathrm{~L}$ of water, under constant stirring. During this process, the $\mathrm{CaO}$ contained in calcined $\mathrm{EG}$ was converted to $\mathrm{Ca}(\mathrm{OH})_{2}$ upon contact with $\mathrm{H}_{2} \mathrm{O}$. Then, $10 \mathrm{~g}$ OPF was added into the solution, stirred (room temperature, $4 \mathrm{~h}$ ), filtered, and oven-dried $\left(80^{\circ} \mathrm{C}, 24 \mathrm{~h}\right)$ to produce EG-OPF. The functional groups of EG-OPF were characterized using Fourier-transform infrared (FTIR) (Nicolet Is5, Thermo Scientific).

\subsection{Adsorption Experiments}

Initially, MB solution was prepared by dissolving the accurate amount of MB (Merck, C.I. 61734 ) in deionized water and the $\mathrm{pH}$ of the solution was adjusted using sodium hydroxide $(\mathrm{NaOH}$, Merck) or hydrochloric acid $(\mathrm{HCl}$, Merck). A specific amount of EG-OPF was added into MB solution (200 mL) under constant stirring (300 rpm, room temperature). The sample was then withdrawn, centrifuged (3800 rpm, $15 \mathrm{~min}$ ) and analysed using UV/Vis spectrophotometer (LAMBDA 850, Perkin Elmer). The adsorption capacity $(\mathrm{mg} / \mathrm{g})$ and percentage removal were calculated using Equations (1) and (2), respectively.

$$
\begin{aligned}
& q_{t}=\left(\frac{C_{o}-C_{t}}{m}\right) x V \\
& \text { Percentage removal }(\%)=\left(\frac{C_{o}-C_{t}}{C_{o}}\right) \times 100
\end{aligned}
$$

Where, $C_{o}(\mathrm{mg} / \mathrm{L})$ and $C_{t}(\mathrm{mg} / \mathrm{L})$ are the MB concentrations at time zero and at time $t$, respectively, $m(\mathrm{~g})$ is the mass of EG-OPF, and $V$ $(\mathrm{L})$ is the volume of MB solution.

\subsection{Experimental Design and Optimization}

The influences of operating conditions on MB removal were optimized using response surface methodology (RSM) coupled with the face-centered central composite design (FCCCD). The RSM was carried out using Sta-

Table 1. Chemical composition in calcined EG

\begin{tabular}{cc}
\hline Compound & Composition (\%) \\
\hline $\mathrm{CaO}$ & 97.44 \\
$\mathrm{MgO}$ & 0.95 \\
$\mathrm{P}_{2} \mathrm{O}_{5}$ & 0.49 \\
$\mathrm{SiO}_{2}$ & 0.25 \\
$\mathrm{Na}_{2} \mathrm{O}$ & 0.21 \\
$\mathrm{Al}_{2} \mathrm{O}_{3}$ & 0.09 \\
$\mathrm{~K}_{2} \mathrm{O}$ & 0.09 \\
$\mathrm{Fe}_{2} \mathrm{O}_{3}$ & 0.04 \\
Others & 0.44 \\
\hline
\end{tabular}


tistica (version 10, Statsoft Inc) with independent variables of the initial concentration of $\mathrm{MB}$ $\left(X_{1}\right)$, initial $\mathrm{pH}\left(X_{2}\right)$, and adsorbent dosage $\left(X_{3}\right)$. The total number of experiments conducted were 16 runs.

\subsection{Kinetic and Isotherm Studies}

The linearized forms of the kinetic models (pseudo-first-order and pseudo-second-order) that used in this study are represented as follows [13,14].

Pseudo-first-order equation:

$$
\ln \left(q_{e}-q_{t}\right)=\ln q_{e}-k_{1} t
$$

Pseudo-second-order equation:

$$
\frac{t}{q_{t}}=\frac{1}{k_{2} q_{e}^{2}}+\frac{1}{q_{e}} t
$$

Where, $q_{e}(\mathrm{mg} / \mathrm{g})$ is the adsorption capacity at equilibrium, $q_{t}(\mathrm{mg} / \mathrm{g})$ is the adsorption capacity at time $t, k_{1}(\mathrm{~L} / \mathrm{min})$ is the pseudo-first-order constant, while $k_{2}(\mathrm{~L} / \mathrm{min})$ is the pseudo-secondorder constant. Meanwhile, the linearized forms of the isotherm models (Freundlich and Langmuir) that used in this study are presented as follows $[15,16]$ :

Freundlich isotherm:

$$
\log q_{e}=\log K_{f}+\frac{1}{n} \log C_{e}
$$

Langmuir isotherm:

$$
\frac{C_{e}}{q_{e}}=\frac{1}{q_{m} K_{L}}+\frac{C_{e}}{q_{m}}
$$

Where, $q_{e}(\mathrm{mg} / \mathrm{g})$ is the adsorption capacity at equilibrium, $\left.K_{f} \quad\left((\mathrm{mg} / \mathrm{g}) .(\mathrm{L} / \mathrm{mg})^{1 / \mathrm{n}}\right)\right)$ is the Freundlich equilibrium constant, $n$ is the heterogeneity factor, and $C_{e}(\mathrm{mg} / \mathrm{L})$ is the $\mathrm{MB}$ concentration at equilibrium. Meanwhile, $K_{L}$ $(\mathrm{L} / \mathrm{mg})$ is the Langmuir constant, $q_{m}(\mathrm{mg} / \mathrm{g})$ is the maximum adsorption capacity, and $C_{e}$ $(\mathrm{mg} / \mathrm{L})$ is the $\mathrm{MB}$ concentration at equilibrium.

\section{Result and Discussion}

\subsection{Characteristic of Adsorbent}

The functional group present on the surface of OPF, fresh EG-OPF, and spent EG-OPF (MB-EG-OPF) were illustrated in Figure 1. A broad peak was detected around 3320 and 3310 $\mathrm{cm}^{-1}$ for OPF and EG-OPF, respectively, which ascribed to the $\mathrm{O}-\mathrm{H}$ stretching mode of hydroxyl groups [17]. The small peaks around $2330 \mathrm{~cm}^{-1}$ attributed to the $\mathrm{C}-\mathrm{H}$ stretching mode of $\mathrm{CH}_{3}$ and $\mathrm{CH}_{2}$ groups [18], while a peak detected around $1030 \mathrm{~cm}^{-1}$ ascribed to the $\mathrm{C} \equiv \mathrm{H}$ and $\mathrm{C}=\mathrm{H}$. Additionally, a peak detected at 1610 $\mathrm{cm}^{-1}$ for $\mathrm{OPF}$ was ascribed to the $\mathrm{C}=\mathrm{O}$ stretching mode of carbonyl group [19]. It was observed that the peak at $1610 \mathrm{~cm}^{-1}$ was shifted to $1420 \mathrm{~cm}^{-1}$, indicating the presence of aromatics groups in EG-OPF. The functional groups involved in the MB adsorption was confirmed by the changes in the intensity and wavenumber of several peaks significantly at 3310, 2330, 1420 , and $1035 \mathrm{~cm}^{-1}$. Thus, it is affirmed that the functional groups of EG-OPF have served to be the active sites for the dye-adsorbent interaction to facilitate the adsorption process.

\subsection{Statistical Analysis}

The experimental design and its results are tabulated in Table 2, while the regression model is given in Equation (7).

$$
\begin{aligned}
Y & =-75.3453+40.9755 X_{1}+43.3118 X_{2} \\
& +0.1079 X_{3}-3.1739 X_{1} X_{2}-0.0175 X_{1} X_{3} \\
& +0.0255 X_{2} X_{3}-3.0180 X_{1}^{2}-9.5961 X_{2}^{2}-0.0001 X_{3}^{2}
\end{aligned}
$$

The ANOVA results, shown in Table 3, confirmed the significance of the model by the greater value of calculated $F$-value $\left(F_{\text {model }}=17.36\right)$ in comparison with the tabulated $F$-value $\left(F_{0.05}=1.409\right)$.

In addition, a high value of $R^{2}(0.9630)$ in parity plot (Figure $2(\mathrm{~A})$ ) revealed the good correlation of the model. The Pareto chart shown in Figure 2(B) discovered that the quadratic term of initial $\mathrm{pH}\left(X_{2}{ }^{2}\right)$, interaction term of initial $\mathrm{pH}$ and adsorbent dosage $\left(X_{2} X_{3}\right)$, interaction term of initial concentration and initial $\mathrm{pH}$ $\left(X_{1} X_{2}\right)$, linear term of adsorbent dosage $\left(X_{3}\right)$, linear term of initial $\mathrm{pH}\left(X_{2}\right)$, and quadratic term of adsorbent dosage $\left(X_{3}^{2}\right)$ were statisti-

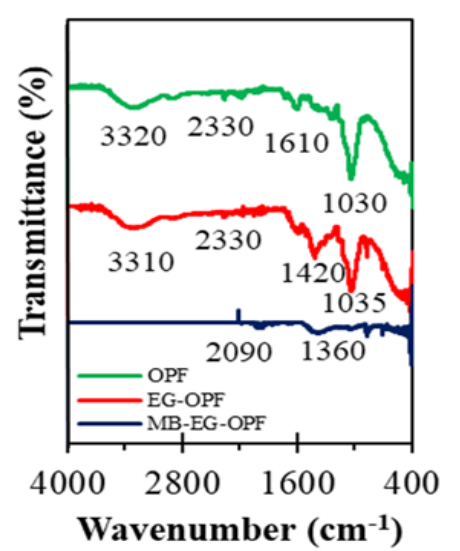

Figure 1. FTIR spectra of OPF, EG-OPF, and MB-EG-OPF 
cally significant due to the large $t$-value magnitude and small $p$-value $(p<0.05)$. The rest of the variables terms were considered less significant, due to a high $p$-value $(p>0.05)$. The quadratic term of initial $\mathrm{pH}\left(\mathrm{X}_{2}{ }^{2}\right)$ was found to be the more prominent variable that highly influenced the MB adsorption onto EG-OPF while the initial concentration $\left(X_{1}\right)$ was the least prominent variable.

Figure 3 displays 3D plots for the influences of independent variables on MB removal. As shown in Figure 3(A), an incline in the initial $\mathrm{MB}$ concentration and initial $\mathrm{pH}$ values simultaneously increased the MB removal until the optimum condition was achieved, and decreased at elevated values. At low initial MB concentration, the quantity of available active sites for adsorption is relatively high, thus increased the MB removal. However, with increasing of $\mathrm{MB}$ concentration, the quantity of available active sites were insufficient to accommodate the superfluous MB ions [4]. For the influence of initial $\mathrm{pH}$, the changes in $\mathrm{MB}$ removal associated with the changes in the surface properties and thus influences the ionization and dissociation of the MB molecule [20].

Figure 3(B) revealed that the interaction between initial concentration and adsorbent dosage was less significant in the MB removal onto EG-OPF, in agreement with result observed by Pareto chart (Figure 2(B)). Figure $3(\mathrm{C})$ displays the influences of initial $\mathrm{pH}$ and adsorbent dosage on MB removal. An increase in initial $\mathrm{pH}$ and adsorbent dosage significantly increased the MB removal until the optimum condition $(\mathrm{pH}=4.9-7$ and adsorbent dosage $=1.0-2.0 \mathrm{~g} / \mathrm{L})$ was achieved and decreased at higher values. This behavior was related to the basic nature of MB, whereby in acidic con-

Table 2. Experimental design of MB removal onto OPF

\begin{tabular}{cccccccc}
\hline \multirow{2}{*}{ Run } & \multicolumn{5}{c}{ Manipulated variables } & Response \\
\cline { 2 - 7 } & $\begin{array}{c}\text { Initial Concentration, } \\
X_{1}(\mathrm{mg} / \mathrm{L})\end{array}$ & \multicolumn{2}{c}{ Initial $\mathrm{pH}, X_{2}$} & Adsorbent dosage, $X_{3}(\mathrm{~g} / \mathrm{L})$ & $\begin{array}{c}\text { MB Removal, } Y \\
(\%)\end{array}$ \\
\cline { 2 - 7 } & Uncoded & Coded & Uncoded & Coded & Uncoded & Coded & 10.05 \\
\hline 1 & 50 & -1 & 2 & -1 & 0.25 & -1 & 9.61 \\
2 & 400 & +1 & 2 & -1 & 0.25 & -1 & 28.15 \\
3 & 50 & -1 & 8 & +1 & 2.5 & +1 & 69.33 \\
4 & 400 & +1 & 8 & +1 & 2.5 & +1 & 55.53 \\
5 & 50 & -1 & 2 & -1 & 0.25 & -1 & 39.83 \\
6 & 400 & +1 & 2 & -1 & 0.25 & -1 & 52.29 \\
7 & 50 & -1 & 8 & +1 & 2.5 & +1 & 35.20 \\
8 & 400 & +1 & 8 & +1 & 2.5 & +1 & 48.68 \\
9 & 225 & 0 & 5 & 0 & 1.375 & 0 & 57.74 \\
10 & 225 & 0 & 5 & 0 & 1.375 & 0 & 64.95 \\
11 & 225 & 0 & 2 & -1 & 0.25 & -1 & 71.52 \\
12 & 225 & 0 & 8 & +1 & 2.5 & +1 & 77.57 \\
13 & 50 & -1 & 5 & 0 & 1.375 & 0 & 76.13 \\
14 & 400 & +1 & 5 & 0 & 1.375 & 0 & 80.27 \\
15 & 225 & 0 & 5 & 0 & 1.375 & 0 & 80.27 \\
16 & 225 & 0 & 5 & 0 & 1.375 & 0 & \\
\hline
\end{tabular}

Table 3. ANOVA analysis for MB removal onto EG-OPF

\begin{tabular}{lcccc}
\hline \multirow{2}{*}{ Sources } & $\begin{array}{c}\text { Sum of square } \\
(S S)\end{array}$ & $\begin{array}{c}\text { Degree of freedom } \\
(\text { d.f })\end{array}$ & $\begin{array}{c}\text { Mean Square } \\
(M S)\end{array}$ & \multirow{2}{*}{-Value } \\
\hline Regression $(S S R)$ & 7951.08 & 9 & 883.45 & 17.36 \\
Residual & 305.38 & 6 & 50.90 & \\
\hline Total $(S S T)$ & 8256.46 & 15 & & \\
\hline
\end{tabular}


dition, the positively charged ions of $\mathrm{MB}\left(\mathrm{H}^{+}\right)$ tend to oppose the cationic EG-OPF adsorption. Meanwhile, in a basic medium, the positively charged ions of $\mathrm{MB}\left(\mathrm{H}^{+}\right)$tend to interact with the negatively charged adsorbent, resulting in an increase in MB removal [21]. At constant $\mathrm{pH}$, an increase in $\mathrm{MB}$ removal with increasing of adsorbent dosage owing to the greater active sites that available for the adsorbent-solute interaction for adsorption.

The process optimization modeling using RSM suggested that the optimal MB removal onto EG-OPF (at $291.71 \mathrm{mg} / \mathrm{L} \mathrm{MB}$ concentration, $\mathrm{pH}$ 5, and $1.82 \mathrm{~g} / \mathrm{L} \mathrm{Eg-OPF)} \mathrm{is} 81.96 \%$. To validate the optimization result, an additional experiment was executed and the corresponding result was obtained at $80.26 \%$.

\subsection{Kinetic and Isotherm Studies}

The kinetic parameters for MB removal onto EG-OPF were listed in Table 4. According to Table 4, the experimental data fitted well with the pseudo-second-order kinetic model $\left(R^{2}>\right.$ 0.990), indicating chemisorption process with the rate of reaction was directly proportional to the number of the active sites.

Table 5 shows the isotherm parameters for MB removal onto EG-OPF. According to Table
5, the adsorption of MB onto EG-OPF was found to follow the Langmuir isotherm model $\left(R^{2}=0.999\right)$, implying the monolayer adsorption on a homogenous adsorbent surface. The obtained $R_{\mathrm{L}}$ value $(0.012)$ confirmed the favorable MB adsorption [22].

\subsection{Reusability Study}

The reusability study was carried out during five adsorption cycle whereby the spent EG-OPF was filtered and oven-dried $\left(80{ }^{\circ} \mathrm{C}, 12\right.$ h) before being used in the next cycle. As can be observed from Figure 4, EG-OPF shows good performance in MB removal even at the $5^{\text {th }}$ cycle of the adsorption process. A slight decrease in adsorption performance during multiple adsorption cycles was related to the existence of MB molecules on the adsorbent surface through chemical bonding after each adsorption process [23].

\section{Conclusion}

EG-OPF was prepared and used as an adsorbent for MB removal. The optimum conditions were achieved at $291.71 \mathrm{mg} / \mathrm{L} \mathrm{MB}$ concentration, $\mathrm{pH}$ 5, and $1.82 \mathrm{~g} / \mathrm{L}$ EG-OPF. FTIR results confirmed the important role of functional
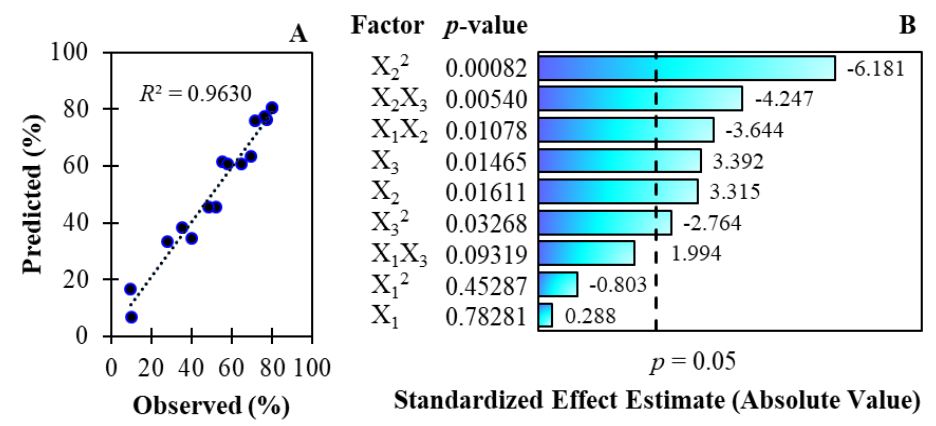

Figure 2. (A) Parity plot and (B) Pareto chart of MB removal onto EG-OPF

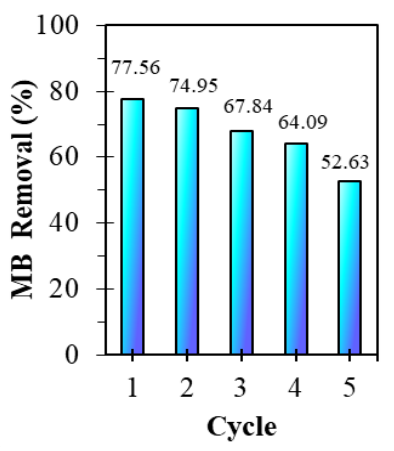

Figure 4. Performance of EG-OPF during five adsorption cycles
A

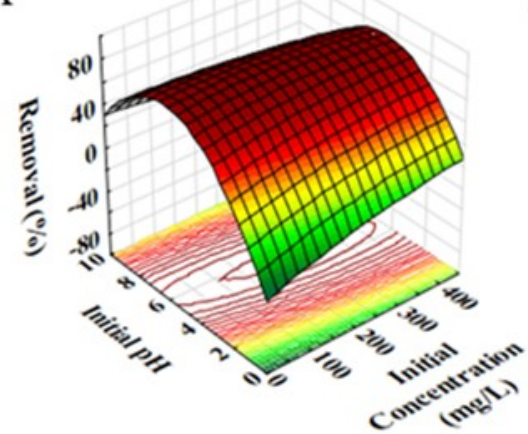

B

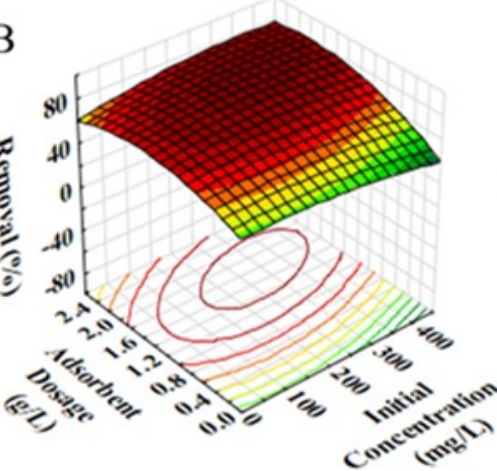

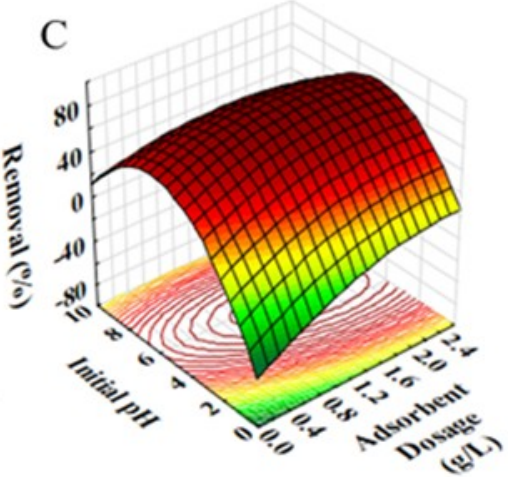

Figure 3. 3D plots of MB removal vs. (A) initial MB concentration and initial $\mathrm{pH}$, (B) initial MB concentration and adsorbent dosage, (C) initial $\mathrm{pH}$ and adsorbent dosage 
Table 4. Kinetic parameters for MB removal onto EG-OPF

\begin{tabular}{|c|c|c|c|c|c|c|c|}
\hline \multirow{2}{*}{$\begin{array}{l}\text { Concentration } \\
(\mathrm{mg} / \mathrm{L})\end{array}$} & \multirow{2}{*}{$\begin{array}{c}\text { Experimental } \\
q_{\mathrm{m}, \exp } \\
(\mathrm{mg} / \mathrm{g})\end{array}$} & \multicolumn{3}{|c|}{ Pseudo-first-order } & \multicolumn{3}{|c|}{ Pseudo-second-order } \\
\hline & & $\begin{array}{c}q_{\mathrm{m}} \\
(\mathrm{mg} / \mathrm{g})\end{array}$ & $\begin{array}{c}k_{1} \\
\left(\mathrm{~min}^{-1}\right)\end{array}$ & $\overline{R^{2}}$ & $q_{\mathrm{m}}(\mathrm{mg} / \mathrm{g})$ & $\begin{array}{c}k_{2} \\
\left(\mathrm{~min}^{-1}\right)\end{array}$ & $R^{2}$ \\
\hline 50 & 79.26 & 2.272 & 0.002 & 0.401 & 78.74 & 0.009 & 0.999 \\
\hline 100 & 153.6 & 7.222 & 0.047 & 0.990 & 158.73 & 0.001 & 0.998 \\
\hline 200 & 283.3 & 8.395 & 0.070 & 0.980 & 303.03 & 0.001 & 0.990 \\
\hline 300 & 386.8 & 12.01 & 0.035 & 0.940 & 400.00 & 0.003 & 0.991 \\
\hline 400 & 469.0 & 7.979 & 0.009 & 0.423 & 476.19 & 0.006 & 0.995 \\
\hline
\end{tabular}

groups in $\mathrm{MB}$ adsorption. Adsorption isotherm study revealed that the MB removal onto EGOPF fitted well with Langmuir isotherm $\left(R^{2}=\right.$ $0.999)$ with $q_{\mathrm{m}}=714.3 \mathrm{mg} / \mathrm{g}$, indicating the monolayer adsorption on a homogenous adsorbent surface. Adsorption kinetic study discovered that the MB removal onto EG-OPF followed the pseudo-second-order kinetic $\left(R^{2}>\right.$ 0.990), indicating the chemisorption process. The feasibility of EG-OPF in MB removal was confirmed by its good activity during five adsorption cycles. This study successfully develops new low-cost adsorbent from waste materials (EG and OPF) for MB removal.

\section{Acknowledgement}

This project was financially supported by the Universiti Malaysia Pahang (UMP) through Research University Grant (RDU170331).

\section{References}

[1] Konicki, W., Aleksandrzak, M., Moszyński, D., Mijowska, E. (2017). Adsorption of Anionic Azo-Dyes from Aqueous Solutions onto Graphene Oxide: Equilibrium, Kinetic and Thermodynamic Studies. Journal of Colloid and Interface Science, 496188-496200.

[2] Tan, K.B., Vakili, M., Horri, B.A., Poh, P.E., Abdullah, A.Z., Salamatinia, B. (2015). Adsorption of Dyes by Nanomaterials: Recent Developments and Adsorption Mechanisms. Separation and Purification Technology, 150229-150242.

[3] Sharma, Y.C., Uma. (2010). Optimization of Parameters for Adsorption of Methylene Blue on a Low-Cost Activated Carbon. Journal of Chemical \& Engineering Data, 55(1): 435-439.

[4] Pathania, D., Sharma, S., Singh, P. (2017). Removal of Methylene Blue by Adsorption onto Activated Carbon Developed from Ficus Carica Bast. Arabian Journal of Chemistry, 10S1445-S1451.
Table 5. Isotherm parameters for MB removal onto EG-OPF

\begin{tabular}{lll}
\hline Isotherm & Parameters & Value \\
\hline Freundlich & $n$ & 1.557 \\
& $K_{f}(\mathrm{mg} / \mathrm{g})(\mathrm{L} / \mathrm{mg})^{1 / n}$ & 3.601 \\
& $R^{2}$ & 0.989 \\
Langmuir & $q_{m}(\mathrm{mg} / \mathrm{g})$ & 714.3 \\
& $K_{L}(\mathrm{~L} / \mathrm{mg})$ & 0.459 \\
& $R^{2}$ & 0.999 \\
& $\mathrm{R}_{\mathrm{L}}$ & 0.012 \\
\hline
\end{tabular}

[5] Alventosa-deLara, E., Barredo-Damas, S., Alcaina-Miranda, M.I., Iborra-Clar, M.I. (2012). Ultrafiltration Technology with a Ceramic Membrane for Reactive Dye Removal: Optimization of Membrane Performance. Journal of Hazardous Materials, 209: 210492-210500.

[6] Körbahti, B.K., Artut, K., Geçgel, C., Özer, A. (2011). Electrochemical Decolorization of Textile Dyes and Removal of Metal Ions from Textile Dye and Metal Ion Binary Mixtures. Chemical Engineering Journal, 173(3): 677688.

[7] Hassani, A., Alidokht, L., Khataee, A.R., Karaca, S. (2014). Optimization of Comparative Removal of Two Structurally Different Basic Dyes Using Coal as a Low-Cost and Available Adsorbent. Journal of the Taiwan Institute of Chemical Engineers, 45(4): 1597-1607.

[8] Tehrani-Bagha, A.R., Nikkar, H., Mahmoodi, N.M., Markazi, M., Menger, F.M. (2011). The Sorption of Cationic Dyes onto Kaolin: Kinetic, Isotherm and Thermodynamic Studies. Desalination, 266(1): 274-280.

[9] Setiabudi, H.D., Jusoh, R., Suhaimi, S.F.R.M., Masrur, S.F. (2016). Adsorption of Methylene Blue onto Oil Palm (Elaeis Guineensis) Leaves: Process Optimization, Isotherm, Kinetics and Thermodynamic Studies. Journal of the Taiwan Institute of Chemical Engineers, 63363-63370. 
[10] Sumathi, S., Chai, S.P., Mohamed, A.R. (2008). Utilization of Oil Palm as a Source of Renewable Energy in Malaysia. Renewable and Sustainable Energy Reviews, 12(9): 24042421.

[11] Saadon, N., Razali, N., Yashim, M.M., Yusof, N.A. (2006). Adsorption of Methylene Blue Using Oil Palm (Elaeis Guaneensis) Fronds as Activated Carbon. ARPN Journal of Engineering and Applied Sciences, 11(9): 61926194.

[12] Djilali, Y., Elandaloussi, E. H., Aziz, A., Menorval L. C. (2016). Alkaline Treatment of Timber Sawdust: A Straightforward Route toward Effective Low-Cost Adsorbent for the Enhanced Removal of Basic Dyes from Aqueous Solutions. Journal of Saudi Chemical Society, 20: S241-S249.

[13] Lagergren, S. (1898). About the Theory of SoCalled Adsorption of Soluble Substances. Journal of Chemical Engineering, 24(1): 1-39.

[14] Ho Y.S., McKay, G. (1999). Pseudo-Second Order Model for Sorption Processes. Process Biochemistry, 34(5): 451-465.

[15] Langmuir, I. (1918). The Adsorption of Gases on Plane Surfaces of Glass, Mica and Platinum, Journal of the American Chemical Society, 40: 1361-1403.

[16] Freundlich, H. (1906). Adsorption in Solution, The Journal of Physical Chemistry, 57: 47385.

[17] Pradeep Sekhar, C., Kalidhasan, S., Rajesh, V., Rajesh, N. (2009). Bio-Polymer Adsorbent for the Removal of Malachite Green from Aqueous Solution. Chemosphere, 77(6): 842847.
[18] Teas, C., Kalligeros, S., Zanikos, F., Stournas, S., Lois, E., Anastopoulos, G. (2001). Investigation of the Effectiveness of Absorbent Materials in Oil Spills Clean Up. Desalination, 140(3): 259-264.

[19] Marín, A.B.P., Ortuño, J.F., Aguilar, M.I., Meseguer, V.F., Sáez, J., Lloréns, M. (2010). Use of Chemical Modification to Determine the Binding of $\mathrm{Cd}(\mathrm{II}), \mathrm{Zn}$ (II) and $\mathrm{Cr}$ (III) Ions by Orange Waste. Biochemical Engineering Journal, 53(1): 2-6

[20] Banerjee, S., Chattopadhyaya, M.C. (2017). Adsorption Characteristics for the Removal of a Toxic Dye, Tartrazine from Aqueous Solutions by a Low Cost Agricultural by-Product. Arabian Journal of Chemistry, 10S1629S1638.

[21] Pirok, B.W.J., Knip, J., van Bommel, M.R., Schoenmakers, P.J. (2016). Characterization of Synthetic Dyes by Comprehensive TwoDimensional Liquid Chromatography Combining Ion-Exchange Chromatography and Fast Ion-Pair Reversed-Phase Chromatography. Journal of Chromatography A, 14361411436146.

[22] Chatterjee, S., Kumar, A., Basu, S., Dutta, S. (2012). Application of Response Surface Methodology for Methylene Blue Dye Removal from Aqueous Solution Using Low Cost Adsorbent. Chemical Engineering Journal, 181: 182289-182299.

[23] Auta, M., Hameed, B.H. (2014). ChitosanClay Composite as Highly Effective and LowCost Adsorbent for Batch and Fixed-Bed Adsorption of Methylene Blue. Chemical Engineering Journal, 237352-237361. 